\title{
Fiber reinforced silicon-containing arylacetylene resin composites
}

\author{
J. Zhang, J. Huang, W. Zhou, F. Huang*, L. Du \\ School of Material Science and Engineering, Key Laboratory for Ultrafine Materials of Ministry of Education, \\ East China University of Science and Technology, 130 Meilong Road, Shanghai 200237, P. R. China
}

Received 27 July 2007; accepted in revised form 8 November 2007

\begin{abstract}
A silicon-containing arylacetylene resin (SAR), a poly(dimethylsilyleneethynylene phenyleneethynylene) (PMSEPE), was synthesized. The PMSEPE is a solid resin at ambient temperature with a softening temperature about $60^{\circ} \mathrm{C}$ and soluble in some solvents like tetrahydrofuran. The melt viscosity of the PMSEPE resin is less than $1 \mathrm{~Pa} \cdot \mathrm{s}$. The resin could cure at the temperature of lower than $200^{\circ} \mathrm{C}$. Fiber reinforced PMSEPE composites were prepared from prepregs which were made by the impregnation of fibers in PMSEPE resin solution. The composites exhibit good mechanical properties at room temperature and $250^{\circ} \mathrm{C}$. The observation on fracture surfaces of the composites reinforced by glass fibers and carbon fibers demonstrates that the adhesion between the fibers and resin is good. The results from an oxyacetylene flame test show that the composites have good ablation performance and XRD analyses indicate that $\mathrm{SiC}$ forms in the residues during the ablation of the composites.
\end{abstract}

Keywords: thermosetting resins, silicon-containing arylacetylene resin, high performance composites, advanced polymer composite, heat and ablation resistance

\section{Introduction}

In recent years, many studies have focused on silicon-containing polymers because of the highly potential applications of the polymers as coatings, adhesives, ceramic precursors, composite matrices, and even conducting materials to aerospace and astronautics, electronics, high-technologies, construction, and so on due to special properties and high thermal stability [1-5]. The silicon-containing polymers with ethynyl or ethynylene groups are interesting and important polymers. Some siliconcontaining polymers with $\left[-\mathrm{SiR}_{2}-\mathrm{C} \equiv \mathrm{C}-\right]$ and $\left[-\mathrm{SiR}_{2}-\mathrm{C} \equiv \mathrm{C}-\mathrm{Ar}-\mathrm{C} \equiv \mathrm{C}-\right]$ units $(\mathrm{R}=$ alkyl or phenyl $)$ have been explored and developed. Itoh, et al. [6-9] firstly prepared poly(phenylsilyleneethynylene-1,3-phenyleneethynylene) (abbreviated as MSP) by a dehydrogenative coupling polymerization reaction between phenylsilane and $m$-diethynyl- benzene in the presence of a magnesia base catalyst. The decomposition temperature of cured MSP resin at $5 \%$ weight loss is $860^{\circ} \mathrm{C}$ and the decomposition residue at $1000^{\circ} \mathrm{C}$ is $94 \%$. Buvat, et al. $[10$, 11] synthesized poly(silyleneethynylene-phenyleneethynylene) terminated with phenylacetylene (abbreviated as BLJ) by polycondensation reaction of dichlorosilane, diethynylbenzene, and phenyl acetylene. The BLJ resin possesses good processability and high heat resistance $\left(T_{g}>450^{\circ} \mathrm{C}\right.$ residue $>80 \%$ at $1000^{\circ} \mathrm{C}$ ).

Recently, our laboratory has been making an effort to develop a kind of silicon-containing arylacetylene resin (SARs). The investigation on poly(dimethylsilyleneethynylene-phenyleneethynylene)s terminated with phenylacetylene was reported, which could cure at the temperature about $230^{\circ} \mathrm{C}$ and shows good processability and high heat

*Corresponding author, e-mail: fhuanglab@ecust.edu.cn

(C) BME-PT and GTE 
resistance $[12,13]$. In this paper, a poly(dimethylsilyleneethynylenephenyleneethynylene) (PMSEPE) resin and fiber reinforced PMSEPE composites were prepared and characterized.

\section{Experimental}

\subsection{Raw materials}

Dimethyldichlorosilane and ethyl bromide (Shanghai No.1 Reagent Factory) were freshly distilled before used. Diethynylbenzene was synthesized and supplied by the Laboratory of Fine Chemicals in East China University of Science and Technology. Magnesium ribbons (Shanghai No.1 Reagents Company) were treated before used. Tetrahydrofuran (THF) and toluene(Shanghai No.1 Reagent Company) were dried over sodium and distilled before used. A plain T300 carbon fabric(T300/3K200P, Toray), a plain glass fabric(SW160-90, Nanjing Glass Fibers Company), T700 unidirectional carbon fibers (Toray), rayon-based carbon fibers (NCF-2, Liaoyuan Chemical Materials Company), and high $\mathrm{SiO}_{2}$ glass fibers (Huate Glass Fiber Company) were used as reinforcements.

\subsection{Analyses and tests}

The molten resin was coated on the a $\mathrm{KBr}$ wafer. The Fourier Transform Infrared (FT-IR) spectrum for the resin was recorded with 32 scans on Nicolet Magna 550. ${ }^{1} \mathrm{H}-\mathrm{NMR}$ and ${ }^{29} \mathrm{Si}-\mathrm{NMR}$ analyses were carried out on a Bruker AVANCE $500(500 \mathrm{MHz})$ spectrometer. Rheological behavior of a resin was traced on a RheoStress RS600 Rheometer at $2{ }^{\circ} \mathrm{C} / \mathrm{min}$ and a shear rate of $0.1 \mathrm{~s}^{-1}$. The flexural property of a composite laminate sample was measured with a Shimadzu AG-50kNE universal tester and MTS Alliance RF/100 tester (USA) according to China Standard GB 3356. The crosshead speed for the tests is $2 \mathrm{~mm} / \mathrm{min}$. The sample dimension was $80.0 \times 12.5 \times 2.0 \mathrm{~mm}^{3}$. The flexural properties for composites at $250,300,400$ and $500^{\circ} \mathrm{C}$ are measured separately in a in-situ temperature-controlled chamber attached to the testers. For the high temperature tests, the samples were kept at the measuring temperature like $400^{\circ} \mathrm{C}$ for 10 minutes before the measure started. XRD analyses were conducted on a Rigaku D/Max 250 VB/PC diffractometer. Scanning electron microscopy (SEM) images were obtained with a JEOL JSM-6360LV microscope. An oxyacetylene flame test for ablation property was performed according to China Standard GJB323A-96 standard on an oxyacetylene ablation apparatus. The pressure and flux of acetylene gas were $0.095 \mathrm{MPa}$ and $1.11 \mathrm{~m}^{3} / \mathrm{h}$ and those of oxygen gas $0.40 \mathrm{MPa}$ and $1.50 \mathrm{~m}^{3} / \mathrm{h}$ for the test, respectively. The temperature of the oxyacetylene flame was measured using an optical pyrometer and reached as high as $2800^{\circ} \mathrm{C}$. The distance between the flame outlet and the sample was $10 \mathrm{~mm}$. The ablation time was 20 second. The sample for the ablation test was a disk with diameter of $\phi 30 \mathrm{~mm}$ and thickness of $10 \mathrm{~mm}$.

\subsection{Synthesis of \\ poly(dimethylsilyleneethynylenephenylene ethynylene) (PMSEPE) resin}

The PMSEPE resin was synthesized by reference to the preparation procedure described in a published article [12]. The treated magnesium ribbons were cut into small pieces. Then $6.00 \mathrm{~g}$ magnesium pieces and $50 \mathrm{ml}$ THF were charged into a threenecked round bottom flask equipped with a condenser, a dropping funnel, a bypass of inert gas and a stirrer. To the flask, $21.6 \mathrm{~g}$ ethyl bromide in $50 \mathrm{ml}$ THF was added dropwise under agitation to produce ethylmagnesium bromide. To the reaction flask, a solution of $11.35 \mathrm{~g}$ diethynylbenzene in $50 \mathrm{ml}$ THF was added dropwise at room temperature for $1 \mathrm{~h}$ and the reaction was continued for an additional 2 hours at the refluxing condition. A solution of $9.29 \mathrm{~g}$ dimethyldichlorosilane in $50 \mathrm{ml}$ THF was dropwise added to the above flask at room temperature over a period of $1 \mathrm{~h}$ with stirring. The reaction was developed for another 2 hours with refluxing. All reactions were carried out under dry nitrogen. After treated by neutralization, abstraction, separation, wash, and distillation, an orange crude resin product was obtained. The yield was $88 \%$. The structure of the synthetic resin is shown in Figure 1. The FT-IR spectrum for the resin is shown in Figure 2. The absorption at $3300 \mathrm{~cm}^{-1}$ is attributed to the vibration of the group $\equiv \mathrm{C}-\mathrm{H}$. The characteristic peak at $2156 \mathrm{~cm}^{-1}$ belongs to the stretching vibration of $\mathrm{C} \equiv \mathrm{C}$ bond. There is a characteristic absorption peak at $1253 \mathrm{~cm}^{-1}$ for the stretching vibration of $\mathrm{Si}-\mathrm{CH}_{3}$ bond. Other analysis results as follows. ${ }^{1} \mathrm{H}-\mathrm{NMR}$ $\left(\mathrm{CDCl}_{3}, \mathrm{TMS}\right): 3.05(\mathrm{~s}, \equiv \mathrm{CH}), 0.37\left(\mathrm{~s}, \mathrm{Si}-\mathrm{CH}_{3}\right)$, 

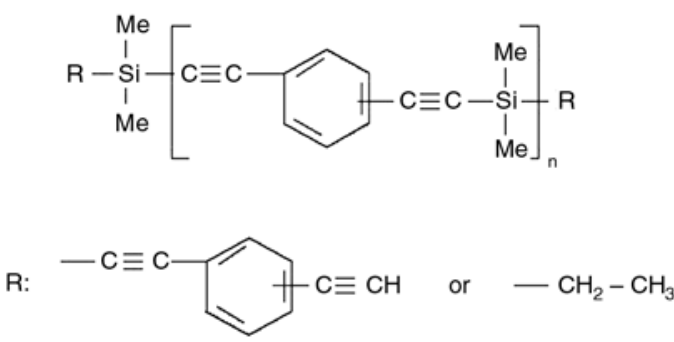

Figure 1. The chemical structure for the PMSEPE resin

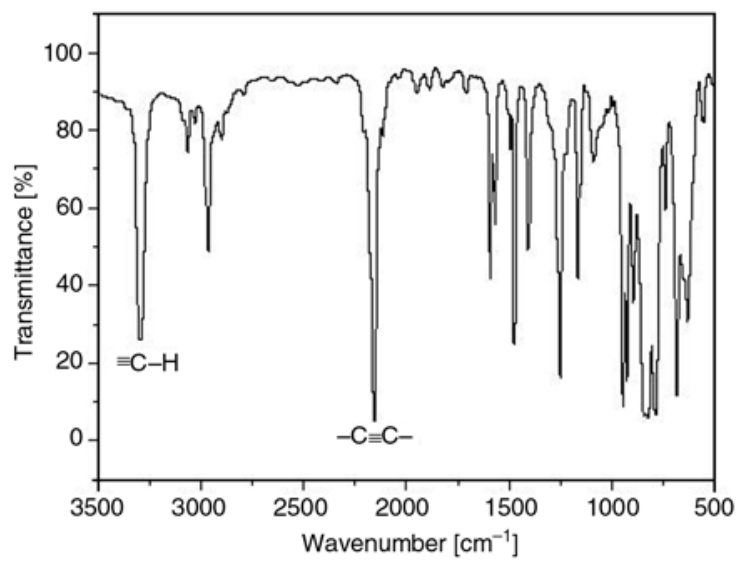

Figure 2. The FT-IR spectrum for the PMSEPE resin

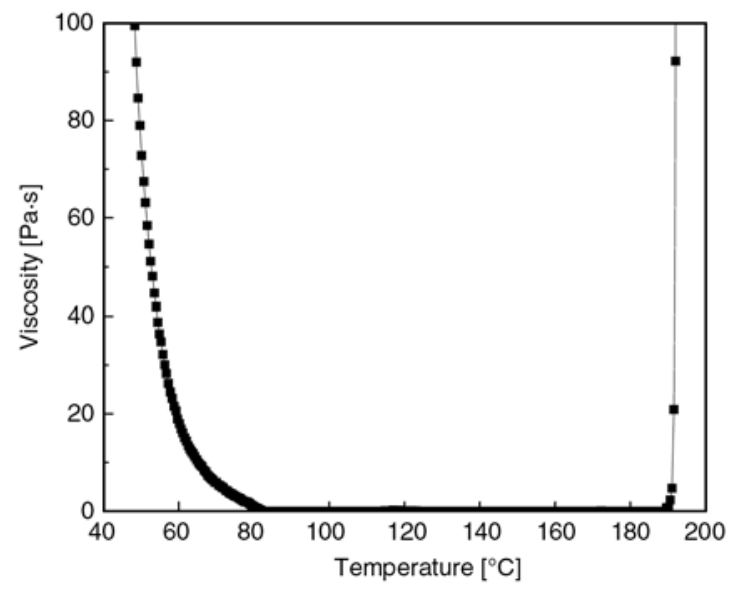

Figure 3. Viscosity-temperature curve of the PMSEPE resin

7.2-7.7(m, Ar-H). ${ }^{29} \mathrm{Si}-\mathrm{NMR}\left(\mathrm{CDCl}_{3}, \mathrm{TMS}\right)$ : -39.0 (s, C $\equiv \mathrm{C}-\mathrm{Si}$ ).

The viscosity response of PMSEPE resin to the temperature ramping at a heating rate of $2^{\circ} \mathrm{C} / \mathrm{min}$ by the rheometer analysis is shown in Figure 3. The viscosity of the resin in the temperature range of 80 to $190^{\circ} \mathrm{C}$ is less than $1 \mathrm{~Pa} \cdot \mathrm{s}$, which would be suitable for the RTM process. Resin viscosity increases rapidly at temperature above $190^{\circ} \mathrm{C}$ due to the further polymerization of the resin. Thereafter, the gelation of the resin occurs.

\subsection{Preparation of composites}

The fabrics (glass: 2D fabric, plain, low alkali Eglass; carbon: 2D fabric, plain, T300) were impregnated with PMSEPE resin solution (37 wt $\%$ resin in THF) and dried in air. An unidirectional prepreg was prepared from unidirectional carbon fibers (T700) and the PMSEPE resin solution by using a drum winding technique. The prepreg was dried on the mandrel to evaporate the solvent and then removed from the drum. The prepregs with good tack and drape were obtained. The content of PMSEPE resin for these prepregs was $35 \mathrm{wt} \%$ ( $c a$ ). The prepregs were then directionally piled up and further dried in a vacuum oven to remove the solvent further if necessary. The piled prepregs were put into a mold and pressed at $170^{\circ} \mathrm{C}$ for $2 \mathrm{~h}, 210^{\circ} \mathrm{C}$ $2 \mathrm{~h}$, and $250^{\circ} \mathrm{C} 4 \mathrm{~h}$ in order under the pressure of $2 \mathrm{MPa}$, successively. For unidirectional composites, an additional treatment process, i. e., $300^{\circ} \mathrm{C}$ $2 \mathrm{~h}$ under the pressure of $2 \mathrm{MPa}$, was applied. Finally, laminated composite boards with thickness of $2.0 \mathrm{~mm} \mathrm{(} \mathrm{ca}$ ) were obtained and the content of cured PMSEPE resin in the composites was $33 \mathrm{wt} \%$ ( $c a$ ). The composite samples for the oxyacetylene flame tests were made from bulk molding compounds (BMC) of PMSEPE resin and short fibers. The short carbon fibers (rayon-based carbon fiber) and short glass fibers (high $\mathrm{SiO}_{2}$ content) with the length of $20-30 \mathrm{~mm}$ were used. The content of the resin in the composite sample was $40 \mathrm{wt} \%(\mathrm{ca})$. The BMC was pressed in a mold at $170^{\circ} \mathrm{C}$ for $2 \mathrm{~h}, 210^{\circ} \mathrm{C} 2 \mathrm{~h}$, and $250^{\circ} \mathrm{C} 4 \mathrm{~h}$ in order under the pressure of 5-6 MPa. The composite composed of glass fibers and PMSEPE resin is denoted as GF-PMSEPE and the composite composed of carbon fibers and PMSEPE resin as CFPMSEPE. The attached number indicate the dimension of fiber distribution in composites: 1 stands for unidirectional fibers, 2 for plain woven fabrics, 3 for disorder short fibers.

\section{Results and discussion}

\subsection{Mechanical properties of composites}

The flexural strength and modulus of fiber reinforced PMSEPE composites at different conditions are shown in Table 1. The flexural strength of GFPMSEPE- 2 composite ( $248 \mathrm{MPa}$ ) at ambient temperature is lower than that of CF-PMSEPE-2 composite $(275 \mathrm{MPa})$, which could result from high 
Table 1. Flexural properties of composites

\begin{tabular}{|l|l|c|c|c|r|}
\hline \multirow{2}{*}{ Specimen } & \multicolumn{1}{|c|}{ Reinforcements } & \multicolumn{2}{c|}{ Flexural strength [MPa] } & \multicolumn{2}{c|}{ Flexural modulus [GPa] } \\
\cline { 3 - 6 } & & $\mathbf{R T}$ & $\mathbf{2 5 0} \mathbf{C}^{\circ} \mathbf{C}$ & $\mathbf{R}$ & $\mathbf{2 5 0}^{\circ} \mathbf{C}$ \\
\hline GF-PMSEPE-2 & glass fabric(2D) & 248 & 268 & 23.9 & 20.6 \\
\hline CF-PMSEPE-2 & T300 carbon fabric(2D) & 275 & 315 & 59.8 & 70.4 \\
\hline CF-PMSEPE-1 & T700 unidirectional carbon fibers & 1495 & 1202 & 118.1 & 105.6 \\
\hline
\end{tabular}

strength of the carbon fiber and good wetting of the resin to carbon fibers. The flexural strength of GFPMSEPE-2 and CF-PMSEPE-2 composites at $250^{\circ} \mathrm{C}$ is a bit higher than that at room temperature probably due to the further curing of the resin at higher temperature, which correspond to the research results of Itoh's group [14]. The modulus for CF-PMSEPE-2 composite increases while GFPMSEPE-2 composite decreases with the temperature rising. This is probably caused by the limit of heat resistance and the decrease of the property for the glass fiber at $250^{\circ} \mathrm{C}$ (the softening point is $\sim 550^{\circ} \mathrm{C}$ ). Nevertheless, the flexural properties of the CF-PMSEPE-1 composite decreased with the temperature as usual. Further investigation on the reinforcing behaviour of the composites will be

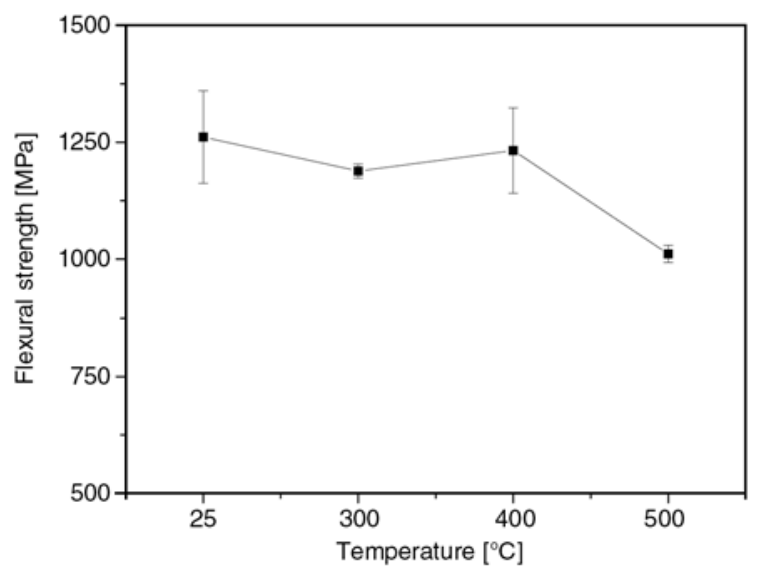

Figure 4. Temperature dependence of flexural strength of the CF-PMSEPE-1 composite

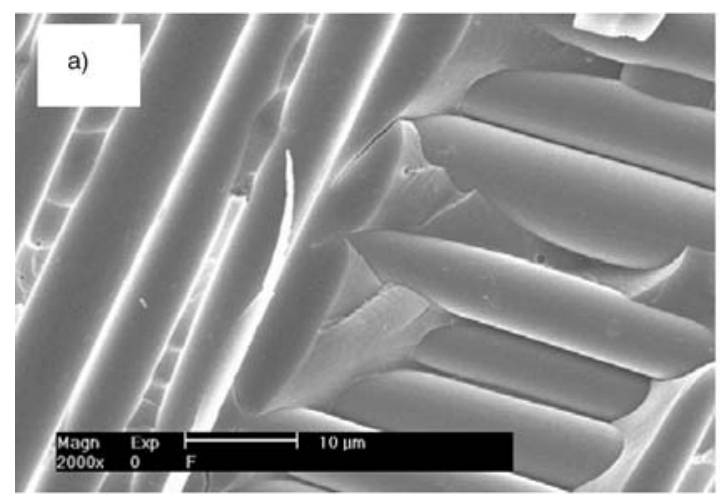

undertaken. Whether or not, those results indicate PMSEPE composites have high heat resistance.

The flexural properties for CF-PMSEPE-1 composite at 300,400 and $500^{\circ} \mathrm{C}$ are measured separately in a temperature-controlled chamber attached to a testing machine. Temperature dependence of flexural strength of CF-PMSEPE-1 composite is shown in Figure 4. The strength of the composites changes a little in the range of 25 to $400^{\circ} \mathrm{C}$. Although the flexural strength decreases as the temperature increases further, the values of the strength for CFPMSEPE- 1 composite at 400 and $500^{\circ} \mathrm{C}$ arrive at as high as 1260 and $985 \mathrm{MPa}$, respectively. This indicates that the composite has excellent mechanical properties at $400-500^{\circ} \mathrm{C}$ and could be expected for the applications at $400^{\circ} \mathrm{C}$.

\subsection{The fracture morphology of composites}

Figure 5 shows the micrographs of the fracture surface of the composites reinforced by glass fabric (GF-PMSEPE-2) and carbon fabric (CF-PMSEPE2). As shown in Figure 5, the surfaces of the fibers and the fracture surfaces of PMSEPE resin on the fracture area of the composites are obviously observed. However, visible separation of the interfaces between the fibers and the resin does not occur. This indicates that the interface adhesion between the fibers and the resin is good, which illustrates that the composites possess high mechanical strength. In addition, more non-wetted fibers in

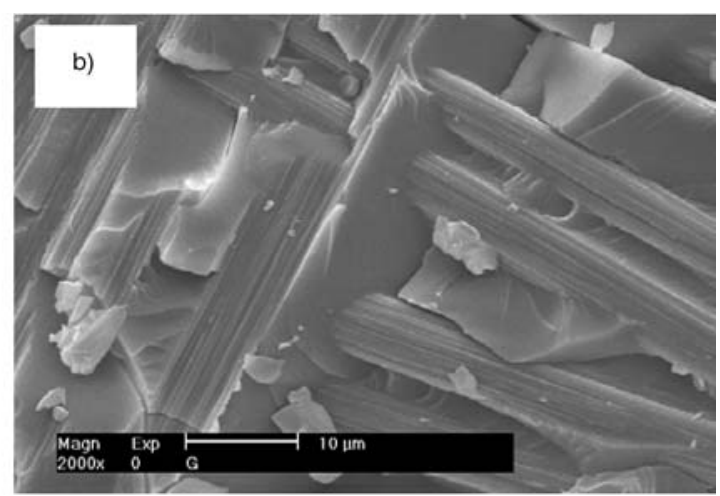

Figure 5. The micrographs of the fracture surface of the composites: a) GF-PMSEPE-2 composite; b) CF-PMSEPE-2 composite 
Figure 5a are observed. This means that the PMSEPE resin wets carbon fibers easier than glass fibers, i. e., the adhesion of the resin to glass fibers is weaker than that to carbon fibers. This also indicates that the PMSEPE resin has more tendency to wet nonpolar fibers like carbon fibers.

\subsection{Ablative properties of composites}

The oxyacetylene flame test was used to evaluate the ablation performance of the composites. Table 2 lists the oxyacetylene flame (ablation) test results for the composites with different reinforcements. As shown in Table 2, the erosion rate of the composites is low, which indicates the PMSEPE resin composites possess good ablation performance. As compared with CF-PMSEPE-3 composite, GF-PMSEPE-3 composite has the higher erosion rates. This probably results from the melting of the glass fibers during the test.

$\mathrm{X}$-ray diffraction analysis results for ablated composites are shown in Figure 6. As shown in Figure 6 , there are three sharp peaks (at $2 \theta=35.58$, 60.02 and $71.78^{\circ}$ ) attributed to $\mathrm{SiC}$ crystals. The peaks for the ablated CF-PMSEPE- 3 composite are more intense than that for the ablated GFPMSEPE-3 composite. This indicates that inorganic SiC ceramic formed after the composites were ablated in the oxyacetylene flame test and the CF-PMSEPE-3 composite was easier to produce $\mathrm{SiC}$ than GF-PMSEPE-3 composite during the ablation. Formation of $\mathrm{SiC}$ with excellent thermal stability would increase the ablation resistance of the composites. In addition, there are broad peaks at 25,35 and $43^{\circ}$ which are related to amorphous $\mathrm{SiO}_{2}$ and carbon in Figure 6. Therefore, amorphous $\mathrm{SiO}_{2}$ and carbon are also present in the ablated products.

Table 2. Ablative properties of composites

\begin{tabular}{|c|c|c|c|c|}
\hline Specimen $^{\mathbf{a}}$ & Reinforcement & Density $\left[\mathbf{g} / \mathbf{c m}^{\mathbf{3}}\right]$ & Line erosion rate $[\mathbf{m m} / \mathbf{s}]$ & Mass erosion rate $[\mathbf{m g} / \mathbf{s}]$ \\
\hline GF-PMSEPE-3 & Glass fibers & 1.49 & 0.122 & 31.4 \\
\hline CF-PMSEPE-3 & Carbon fibers & 1.26 & 0.040 & 15.3 \\
\hline
\end{tabular}

aThe composites made from the dough molding compound of the resin and short fibers
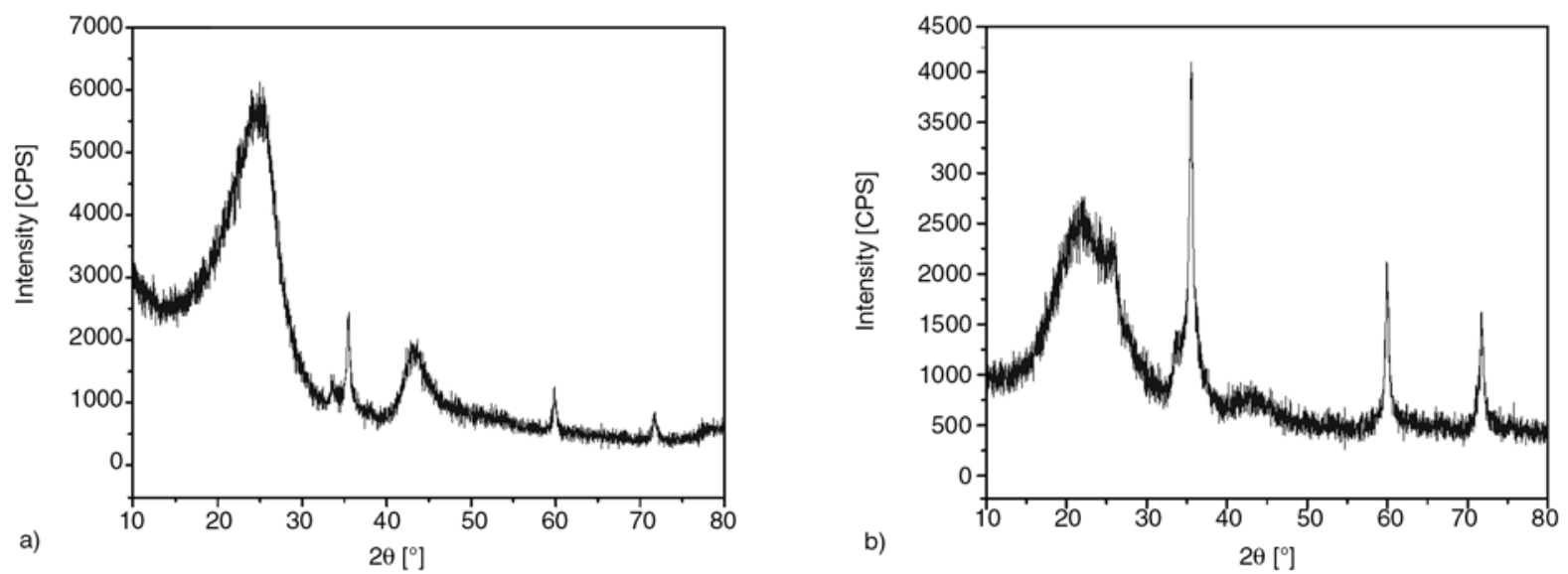

Figure 6. XRD spectrogram of the ablated composites: a) GF-PMSEPE-3; b) CF-PMSEPE-3
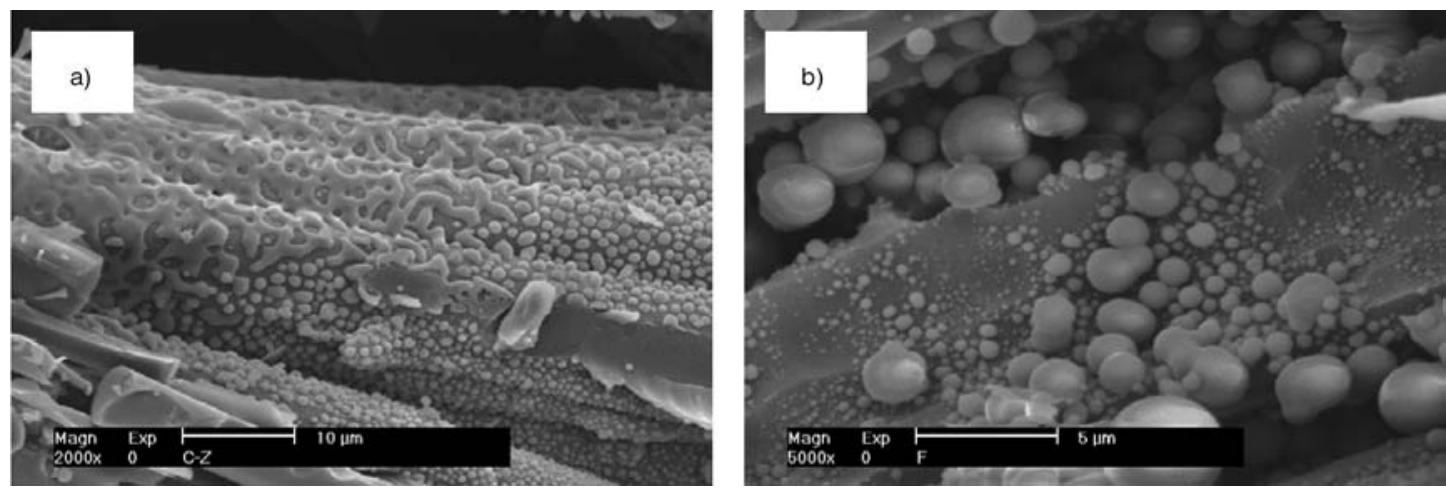

Figure 7. SEM of the ablated composites: a) GF-PMSEPE-3; b) CF-PMSEPE-3 
The morphology of the ablated composites was observed by scanning electron microscopy (SEM). The micrographs are shown in Figure 7. As shown in Figure 7a, there are some particles and network substances like aggregated melt liquid drops on the surface of glass fibers after the ablation of GFPMSEPE-3 composite, which possibly results from partially melted glass fibers. Figure $7 \mathrm{~b}$ shows that there are particles with different sizes on the surface of carbon fibers or among the carbon fibers and that some carbon fibers have been ablated. Therefore, the destruction of composites occurs due to the decomposition of PMSEPE resin and the melting or burning of the fibers. The particles produced would be $\mathrm{SiC}, \mathrm{SiO}_{2}$, etc. Further analyses and determination of the particles are under the way.

\section{Conclusions}

Poly(dimethylsilyleneethynylenephenyleneethynylene) (PMSEPE) resin was synthesized and the resin composites reinforced by different fibers were prepared. The fibers reinforced PMSEPE composites show good mechanical properties at room temperature and $250-400^{\circ} \mathrm{C}$ and good ablation performance. The resin could be expected to be used as an important high performance matrix for advanced composite materials.

\section{Acknowledgements}

The authors gratefully thank the National Basic Research Program of China (Grant No. 51318020006) and the National High Technology Research and Development Program of China (Grant No. 2002AA305205) for the financial supports.

\section{References}

[1] Ichitani M., Nakamura K.: Cured product of carborane-containing silicon-base resin. Japanese patent, JP 2000309635, Japan (2000).

[2] Ito M., Inoue K., Hirayania N., Sugimoto M., Seguchi T.: Fiber reinforced composites with a new heat-resistant polymer matrix containing silicon. Journal of the Japan Society for Composite Materials (in Japanese), 27, 188-193 (2001)
[3] Buvat P., Jousse F., Gerard J-F., Nony F.: Compositions with poly(ethynylene phenylene ethynylene silylenes). French Patent, FR 2836922, France (2003).

[4] Narisawa M., Tanaka E., Nishimura R., Okamura K., Itoh M., Kamiyama T.: Synthesis and characterization of carbon-based hybrid ceramics in coating form from thermosetting resin-alkoxide mixtures. Key Engineering Materials: Advanced Ceramics and Composites, 247, 137-140 (2003).

[5] Inoue K., Iwata K., Ishikawa J., Fujikake S., Itoh M.: Silicon-containing polymers for manufacture of ceramic moldings. Japanese patent, JP 19970428, Japan (2003).

[6] Itoh M., Inoue K., Iwata K., Mitsuzuka M., Kakigano T.: New highly heat-resistant polymers containing silicon: Poly(silyleneethynylenephenyleneethynylene)s. Macromolecules, 30, 694-701 (1997).

[7] Itoh M., Mitsuzuka M., Iwata K., Inoe K.: Siliconcontaining carbon materials. Japanese patent, JP 19941124, Japan (1994).

[8] Itoh M., Mitsuzuka M., Iwata K., Inoe K.: Siliconcontaining fire-resistant materials. Japanese patent, JP 19940712, Japan (1994).

[9] Itoh M., Inoue K., Iwata K., Mitsuzuka M., Nara R., Hirayama N.: Highly heat-resistant polymers containing silicon: poly(silyleneethynylenephenyleneethynylene)s. Journal of Network Polymer (in Japanese), 17, 161-168 (1996).

[10] Buvat P., Jousse F., Delnaud L., Levassort C.: Synthesis and properties of new processable type polyarylacetylenes. in 'International SAMPE Symposium and Exhibition 2001, Long Beach, USA' 134-144 (2001).

[11] Buvat P., Levassort C., Jousse F.: Poly(silyleneethynylenephenyleneethynylene) and methods for preparing same. French Patent, FR 2798662, France (2001).

[12] Wang F., Zhang J., Huang J., Yan H., Huang F., Du L.: Synthesis and characterization of poly(dimethylsilyleneethynylenephenyleneethynylene) terminated with phenylacetylene. Polymer Bulletin, 56, 19-26 (2006).

[13] Zhang J., Zhou W., Huang J. X., Wang F., Gao F., Huang F. R., Du L.: The property investigation of a novel silicon-containing arylacetylene resin and its composite. in 'Proceeding of $14^{\text {th }}$ National Conference on Composite Materials of China, Wuhan, China' (in Chinese) 472-476 (2006).

[14] Itoh M., Inoue K., Hirayama N., Sugimoto M., Seguchi T.: Fiber reinforced plastics using a new heatresistant silicon based polymer. Journal of Materials Science, 37, 3795-3801 (2002). 